\title{
Solar UV-B Radiation Influences Carotenoid Accumulation of Tomato Fruit through Both Ethylene-Dependent and - Independent Mechanisms
}

\author{
Elisa Becatti,${ }^{\dagger}$ Katia Petroni,${ }^{*}$ Deborah Giuntini $,{ }^{\dagger}, \S$ Antonella Castagna,${ }^{\dagger}$ \\ Valentina Calvenzani, ${ }^{\ddagger}$ Giovanni Serra,${ }^{\S}$ Anna Mensuali-Sodi, ${ }^{\S}$ \\ Chiara Tonelli, ${ }^{*}$ and Annamaria Ranieri $*{ }^{*}$
}

\begin{abstract}
'Department of Agricultural Chemistry and Biotechnology, University of Pisa, via del Borghetto 80, I-56124 Pisa, ${ }^{*}$ Department of Biomolecular Sciences and Biotechnology, University of Milan, via Celoria 26, I-20133 Milano, and \$Sant’Anna School of Advanced Studies, Piazza Martiri della Libertà 33, I-56127 Pisa
\end{abstract}

\begin{abstract}
The effect of UV-B shielding on ethylene production in ripening tomato fruits and the contribution of ethylene and UV-B radiation on carotenoid accumulation and profile during ripening were assessed to get more insight about the interplay between these two regulatory factors. To this aim, rin and nor tomato mutants, unable to produce ripening ethylene, and cv Ailsa Craig were cultivated under control or UV-B depleted conditions until full fruit ripening. The significantly decreased ethylene evolution following UV-B depletion, evident only in Ailsa Craig, suggested the requirement of functional rin and nor genes for UVB-mediated ethylene production. Carotenoid content and profile were found to be controlled by both ethylene and UV-B radiation. This latter influenced carotenoid metabolism either in an ethylene-dependent or -independent way, as indicated by UVB-induced changes also in nor and rin carotenoid content and confirmed by correlation plots between ethylene evolution and carotenoid accumulation performed separately for control and UV-B shielded fruits. In conclusion, natural UV-B radiation influences carotenoid metabolism in a rather complex way, involving ethylene-dependent and -independent mechanisms, which seem to act in an antagonistic way.
\end{abstract}

KEYWORDS: Ailsa Craig; carotenoids; ethylene; Lycopersicon esculentum; nor; tomato; rin; UV-B radiation

\section{INTRODUCTION}

The basic nutritional value of foodstuffs is influenced to a considerable extent by endogenous factors as well as by external stimuli such as the environmental conditions prevalent during crop production and fruit ripening (1). Due to the highly interactive network of metabolic pathways present in all plant tissues, even minor environmental changes have in fact the potential to lead to significant perturbations in the content of nutritionally relevant metabolites (2).

The different light wavelengths regulate a plethora of plant developmental and metabolic processes through perception and transduction of the light signal. Despite that ultraviolet-B $(\mathrm{UV}-\mathrm{B})$ radiation represents only a small fraction of total solar radiation, it is known to elicit a variety of responses in higher plants (3). Differently from phytochrome- and cryptochromemediated responses, the knowledge about $\mathrm{UV}-\mathrm{B}$ sensing and downstream signaling is scarce. The nature of UV-B photoreceptor(s) is still unknown, and few data are available on the events following UV-B perception (4). In Arabidopsis, the

*Corresponding author. Telephone: +39 (0)50 2216605. Fax: +39 (0)50 2216630. E-mail: aranieri@agr.unipi.it. transcriptional responses to low level $\mathrm{UV}-\mathrm{B}$ are mediated by a specific pathway involving the UVR8 protein (UVR8), the repressor of photomorphogenesis COP1 and the photomorphogenesis-promoting factors HY5 and HY5 HOMOLOGUE (5-7). In the presence of UV-B, UVR8 moves from cytosol into the nucleus, where it binds the promoter of HY5 and activates its transcription (5). Recently, the finding that UVR8 and COP1 directly interact in a UV-B-dependent manner in the nucleus suggests a role for this interaction as an early step in the response to $\mathrm{UV}-\mathrm{B}(8)$.

Leaf carotenogenesis is believed to be controlled by light quality through the action of phytochrome and/or UV-B receptors $(9,10)$, the former regulating carotenoid accumulation at the level of phytoene synthase (Psy) expression (9). Alba et al. (11) reported that brief red-light treatments stimulated carotenogenesis of harvested mature-green fruits of tomato and that red-light-induced pigmentation was reversed by far-red light, thus demonstrating that phytochrome controls light-induced pigmentation also in fruits. Moreover, since fruit-localized phytochrome did not affect ethylene biosynthesis in ripening tomatoes, such a phytochrome-mediated regulation of carotenoid biosynthesis occurred independently of ethylene (11). 
The phytohormone ethylene regulates many aspects of plant growth, development, and senescence and also plays an important role as a signaling molecule in the response to biotic and abiotic stresses (12). In climacteric fruits like tomato, this hormone has an essential regulatory role in the ripening process (13). During ripening, ethylene production switches from system 1, operating during growth, development, and stress responses, to system 2, which functions during flower senescence and fruit ripening. Differently from system 1 type ethylene production, which is autoinhibitory, system 2 is autocatalytic, being stimulated by ethylene itself (13). Although ethylene production during fruit ripening is well characterized, the upstream molecular and biochemical events which initiate ripening-related ethylene production are still largely unknown.

By using ethylene-insensitive transgenic tobacco plants, Pierik and co-workers (14) demonstrated a critical role for ethylene as a component of blue light-mediated stem elongation in the shade avoidance process. In seedlings, ethylene production is known to be strongly inhibited by active phytochrome (15) and stimulated by phytochrome deactivation following lowered R:FR ratio (16). The present work is addressed to verify whether, in ripening tomato fruits, ethylene production can be modulated by natural $\mathrm{UV}-\mathrm{B}$ radiation, which may thus act as a regulatory factor upstream of ethylene signaling in the ripening process. Moreover, based on previous data obtained in our laboratory on the effects of solar UV-B depletion on tomato carotenoid pattern (17), we attempted to elucidate the contribution of ethylene and UV-B radiation on carotenoid accumulation and profile during fruit ripening and to get more insight about the interplay between these two regulatory factors. To this aim, two ripening-impaired recessive mutants, rin (ripening-inhibitor) and nor (nonripening), which do not exhibit ripening-related ethylene production and fail to undergo a normal ripening program, and the wild type, cv Ailsa Craig, were cultivated under control or $\mathrm{UV}-\mathrm{B}$ depleted conditions until full fruit ripening.

\section{MATERIALS AND METHODS}

Chemicals. All the reagents were of analytical or HPLC grade. Butylated hydroxytoluene (BHT), Celite Filter Cel, lycopene, $\beta$-carotene, lutein, and the other reagents were purchased from Sigma Aldrich (Milan, Italy) and organic solvents from Mallinckrodt Baker Italia (Milan, Italy). Water used as HPLC mobile phase was Milli-Q (Millipore, Bedford, MA) purified water.

Plant Material. Three tomato (Lycopersicon esculentum L.) genotypes were used: the wild type cv Ailsa Craig (LA2838A) and two ripeningimpaired recessive mutants rin (LA3754) and nor (LA3770), which do not exhibit ripening-related ethylene production and fail to undergo a normal ripening program. Seeds were supplied by the C.M. Rick Tomato Genetics Resource Center (Department of Plant Sciences, University of California Davis, Davis, CA, USA). Both the rin and nor loci have been isolated. More in detail, Vrebalov et al. (18) showed that the rin locus harbors two tandem MADS-box genes, one of which, designated LeMADS-RIN, regulates fruit ripening. Similarly to the wild-type protein, the rin mutant protein accumulates in fruit and exhibits a DNA-binding activity, but it has lost the transcription-activating function (19). Detailed information on the nor gene has not been published, but it has been suggested that it encodes a transcription factor, although not a member of the MADS-box family (20).

Growth Conditions. Seeds of the two tomato genotypes were sown, in plug trays with a peat/perlite $(3: 1 \mathrm{v} / \mathrm{v})$ medium, four times (each separated by 1 week), and the fruits were harvested at the same time at two ripening stages. Plants were grown in a heated glasshouse under natural light conditions, watered daily, and received 20N-20P-20K soluble fertilizer $\left(1 \mathrm{~g} \mathrm{~L}^{-1}\right)$ once a week. About 45 days after sowing, when the seedlings had reached the stage of four true leaves, the tomato plants were transplanted into pots containing the same medium and fertilized weekly with $24 \mathrm{~N}-8 \mathrm{P}-16 \mathrm{~K}$. The tomato plants were kept in the glasshouse (UV-B-free) until 1 week before the breaker stage of the first truss of fruits. The plants were then transferred in May into two tunnels covered by polyethylene films (Agraria Di Vita, Pescia, Pistoia, Italy) with different light screening properties. In one tunnel, covered by polyethylene film, the plants were subjected to the whole sunlight spectrum conditions (control fruits), whereas in the second tunnel covered by polyethylene film stabilized with the $\mathrm{UV}-\mathrm{B}$ absorber benzophenone, the plants were kept in the absence of $\mathrm{UV}-\mathrm{B}$ (UV-B shielded fruits). The irradiance spectrum under the two polyethylene tunnels, measured at midday by a spectroradiometer (SpectraMED mod 2085, FlyBy, Livorno, Italy), revealed that benzophenone-treated polyethylene film screened $75-95 \%$ of UV-B radiation $(280-320 \mathrm{~nm})$. The screening capacity quickly dropped to $35 \%$ at $328 \mathrm{~nm}$, and starting from $330 \mathrm{~nm}$, no differences were detected between the two covering films. Details on irradiance spectrum in the UV region under two kinds of polyethylene films used to cover the tunnels and further information about growth conditions are reported in Giuntini et al. (21). Tomato harvesting was performed at the mature green (MG), breaker (BR), and red ripe (RR) stages, and the ripeness stage was characterized in accordance with the procedure reported by Grierson and Kader (22). Healthy fruits of comparable dimension were carefully harvested from sunny branches.

Flesh and peel samples were collected separately. Each sample was frozen by liquid nitrogen and stored at $-80{ }^{\circ} \mathrm{C}$ until analysis. Fresh tomatoes were homogenized, and biochemical parameters were determined on three groups of fruits at each ripening stage consisting of 20 fruits randomly chosen from each batch.

Quantification of Ethylene Emission. Individual fruits were incubated within sealed containers at room temperature, and after $30 \mathrm{~min}, 2$ $\mathrm{mL}$ samples were withdrawn with a hypodermic syringe. Ethylene evolution was measured by injecting samples into a gas chromatograph equipped with a dual flame ionization detector and a metal column $(150 \times$ $0.4 \mathrm{~cm}$ internal diameter) packed with alumina (70-230 mesh). The column and detector temperatures were 70 and $350{ }^{\circ} \mathrm{C}$, respectively. Nitrogen was used as a carrier at a flow rate of $40 \mathrm{~mL} \mathrm{~min}^{-1}(23)$.

Carotenoids and Chlorophylls Extraction and Determination. Carotenoids were extracted according to the method reported by Giuntini et al. (17). Briefly, flesh and skin samples were homogenized in an UltraTurrax homogenizer and extracted with tetrahydrofuran (THF) stabilized with $0.01 \%$ BHT. Magnesium carbonate, for buffering the acidic environment, and Celite Filter Cel, as a filter aid, were added to the homogenized sample, each at $10 \%$ of sample weight for flesh and at $100 \%$ and $200 \%$, respectively, for skin samples. Extractions were repeated 5 times, and the volume of the combined THF extracts was reduced by two-thirds under vacuum at $35{ }^{\circ} \mathrm{C}$ on a rotary evaporator. Components of the combined extracts were portioned into dichloromethane and $\mathrm{NaCl}$ saturated water in a separating funnel. The water layer was washed with dichloromethane until carotenoids were completely removed. The organic layers were combined, and the volume was reduced to $2-4 \mathrm{~mL}$ under vacuum at $35^{\circ} \mathrm{C}$, filtered through a $0.22 \mu \mathrm{m}$ filter (Sartorius, Goettingen, Germany), and injected into the column (Phenomenex Prodigy LC-18 ODS, $250 \times 4.6 \mathrm{~mm}, 5 \mu \mathrm{m}$ with guard column Phenomenex AJO-4287 C18 ODS, Phenomenex srl, Castel Maggiore, Italy). The analytical separation of carotenoid extracts was performed by Spectra SYSTEM P4000 HPLC equipped with a UV 6000 LP photodiode array detector (Thermo Fisher Scientific, Waltham, MA, USA).

Gradient elution was performed using solvent A (acetonitrile/hexane/ methanol/dichloromethane, 4:2:2:2) and solvent B (acetonitrile) as mobile phases at a flow rate of $0.8 \mathrm{~mL} / \mathrm{min}$. The gradient program was as follows: $0-20 \mathrm{~min}, 100 \% \mathrm{~A} ; 20-38 \mathrm{~min}, 60 \% \mathrm{~A}$ and $40 \% \mathrm{~B} ; 38-45 \mathrm{~min}, 100 \% \mathrm{~A}$. Carotenoids were quantified by comparison of UV-vis spectra and retention times of eluted compounds with pure standard for lycopene, lutein, and $\beta$-carotene at $450 \mathrm{~nm}$. Furthermore, to quantify phytofluene and phytoene, their respective peak areas at 350 and $290 \mathrm{~nm}$ were compared with those of standard lycopene at known concentrations, established by the molar extinction coefficient in acetone reported in the literature and corrected by the molar extinction coefficient relative at each compound (17).

Statistic. Values reported in tables and figures are the means \pm SE of three replications. The effects of genotype, ripening stage, and presence or absence of $\mathrm{UV}-\mathrm{B}$ radiation and of their interactions were evaluated by three-way analysis of variance (ANOVA). The significance level was set at 


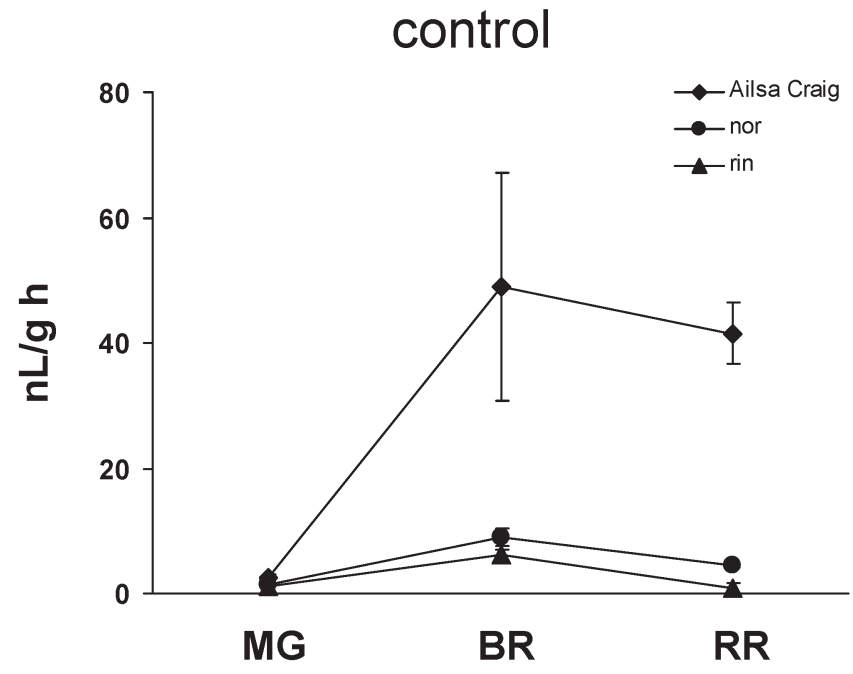

UV-B depleted

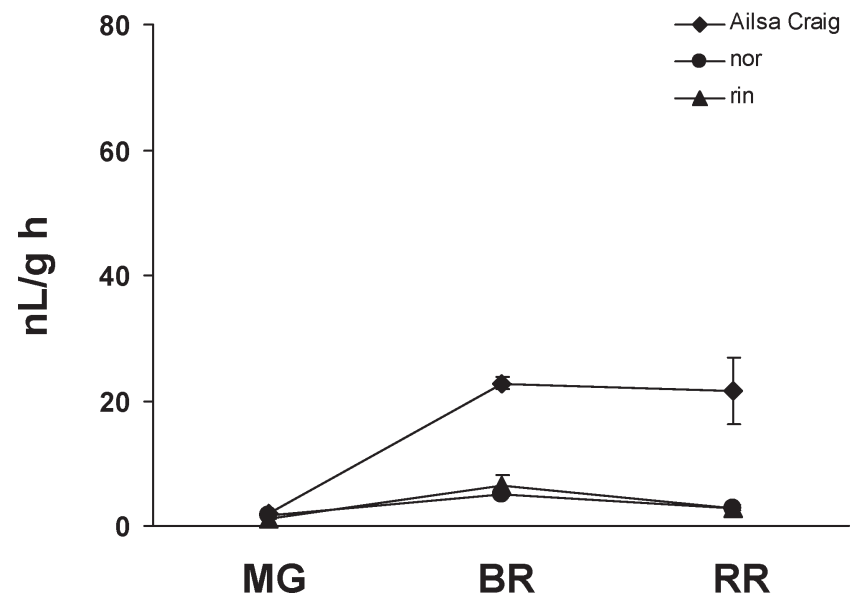

\begin{tabular}{lc}
\hline FACTORS & $\begin{array}{r}\text { Ethylene } \\
\mathrm{nL} \mathrm{g}^{-1} \mathrm{~h}^{-1}\end{array}$ \\
\hline Genotype (A) & \\
Ailsa-Craig & $\mathbf{2 3 . 1 5} \mathbf{~ a}$ \\
nor & $\mathbf{4 . 0 7} \mathbf{~ b}$ \\
rin & $\mathbf{3 . 1 2} \mathbf{b}$ \\
P-value & $0.000^{*}$ \\
\hline Ripening (B) & \\
MG & $\mathbf{1 . 6 3} \mathbf{~ c}$ \\
BR & $\mathbf{1 6 . 0 4} \mathbf{~ a}$ \\
RR & $\mathbf{1 2 . 3 1} \mathbf{b}$ \\
P-value & $0.000^{*}$ \\
\hline (A)x(B) & \\
P-value & $0.000^{*}$ \\
\hline UVB (C) & \\
+ UVB & $\mathbf{1 2 . 8 6} \mathbf{~ a}$ \\
- UVB & $\mathbf{7 . 3 8 ~ b}$ \\
P-value & $0.000^{*}$ \\
\hline (A)x(C) & \\
P-value & $0.000^{*}$ \\
\hline (B)x(C) & \\
P-value & $0.009^{*}$ \\
\hline (A)x(B)x(C) & \\
P-value & $0.010^{*}$ \\
\hline
\end{tabular}

Figure 1. Ethylene production (expressed as $\mathrm{nL}^{-1} \mathrm{~h}^{-1}$ ) of Ailsa Craig, nor, and rin tomato fruits during ripening (MG, mature green; $\mathrm{BR}$, breaker stage; RR, red ripe stage) under control or UV-B-depleted conditions. Data represent the mean + SE of three measurements. The results of three-way ANOVA for the effect of genotype (A), ripening stage (B), presence or absence of UV-B radiation (C), and of their interactions are reported in the table. The significance of the $P$-value according to three-way ANOVA is reported. Asterisk $\left(^{*}\right)$ indicates statistically significant differences at $P<0.05$. Different letters indicate statistically different means following Tukey's test $(P=0.05)$.

$P=0.05$. Separation of means was performed by Tukey's test at the 0.05 significance level.

The significance level $(P)$ of the correlation coefficients $(R)$ of linear regression equations between ethylene emission and total or single carotenoid concentration was determined using the Student's t distribution.

\section{RESULTS}

Ethylene Emission. Ethylene production was significantly influenced by genotype, ripening stage, and UV-B depletion treatment, as well as by the interactions among the factors, as indicated by the three-way ANOVA (Figure 1). Rin and nor mutants were shown to evolve similar amounts of ethylene which were considerably lower in comparison to Ailsa Craig. Moreover, while Ailsa Craig fruits evolved high and similar ethylene amounts at the BR and RR stage, the two mutants did not show any significant increase in ethylene emission as ripening proceeded (Figure 1). UV-B depletion induced a significant decrease in ethylene emission (about $-43 \%$, Figure 1), which was evident only in Ailsa Craig fruits and was ripening-dependent, occurring at the BR $(-46 \%)$ and RR stages (-42\%, Figure 1).
Chlorophyll and Carotenoid Concentration. Three-way ANOVA was performed to determine whether chlorophyll and carotenoid concentration in skin and flesh of fruits (Tables $\mathbf{1}$ and $\mathbf{2}$, respectively) were influenced by genotype, ripening stage, UV-B depletion, and the interactions among these factors.

Total Chlorophyll. Skin total chlorophyll concentration was significantly affected by genotype, Ailsa Craig, and rin mutant exhibiting the highest and the lowest concentration, respectively (Table 1). As expected, chlorophyll was present at the MG stage and decreased to not detectable values starting from the BR stage either in Ailsa Craig or in the two mutants. Fruit ripening under UV-B shielded conditions led to a significant reduction in skin chlorophyll concentration of about $-31 \%$ (Table 1). Since chlorophyll was not detected at BR and RR stages, the negative effect of UV-B depletion was observed only in MG skin, when nor showed the major decrease $(-41 \%$, Table 3$)$.

At the flesh level, Ailsa Craig and nor fruits contained similar chlorophyll concentration, which was about 7-fold that of rin (Table 2). As already observed in the skin, chlorophyll was detected only at the MG stage and was negatively affected by 
Table 1. Effect of Genotype (A), Ripening Stage (B), Presence or Absence of UV-B Radiation (C), and Their Interactions on Total Chlorophyll, Total Carotenoid, Lycopene, $\beta$-Carotene, Lutein, Phytoene and Phytofluene Concentration of Tomato Fruit Skin ${ }^{a}$

\begin{tabular}{|c|c|c|c|c|c|c|c|}
\hline & tot chlor & tot carot & lycopene & $\beta$-carot & lutein & phytoene & phytofluene \\
\hline factor & $\mathrm{mg} 100 \mathrm{~g}^{-1} \mathrm{fw}$ & $\mathrm{mg} 100 \mathrm{~g}^{-1} \mathrm{fw}$ & $\mathrm{mg} 100 \mathrm{~g}^{-1} \mathrm{fw}$ & $\mathrm{mg} 100 \mathrm{~g}^{-1} \mathrm{fw}$ & $\mathrm{mg} 100 \mathrm{~g}^{-1} \mathrm{fw}$ & $\mathrm{mg} 100 \mathrm{~g}^{-1} \mathrm{fw}$ & $\mu \mathrm{g} 100 \mathrm{~g}^{-1} \mathrm{fw}$ \\
\hline
\end{tabular}

\begin{tabular}{|c|c|c|c|c|c|c|c|}
\hline \multicolumn{8}{|c|}{ Genotype (A) } \\
\hline Ailsa Craig & $4.16 \mathrm{a}$ & $6.27 a$ & $3.29 a$ & $0.99 a$ & $1.00 \mathrm{a}$ & $0.98 a$ & $3.07 \mathrm{a}$ \\
\hline nor & $0.30 \mathrm{~b}$ & $1.52 \mathrm{c}$ & $0.07 b$ & $0.26 b$ & $0.57 \mathrm{~b}$ & $0.61 b$ & $1.97 b$ \\
\hline rin & $0.16 c$ & $2.11 \mathrm{~b}$ & $0.13 b$ & $0.29 b$ & $1.00 \mathrm{a}$ & $0.68 b$ & $3.15 \mathrm{a}$ \\
\hline$P$-value & $0.000^{*}$ & $0.000^{*}$ & $0.000^{*}$ & $0.000^{*}$ & $0.000^{*}$ & $0.000^{*}$ & $0.000^{*}$ \\
\hline \multicolumn{8}{|c|}{ Ripening (B) } \\
\hline$M G$ & $4.66 \mathrm{a}$ & $1.40 \mathrm{C}$ & $0 c$ & $0.23 c$ & $1.09 \mathrm{a}$ & $0.07 \mathrm{c}$ & $0 \mathrm{c}$ \\
\hline $\mathrm{BR}$ & $0 \mathrm{~b}$ & $3.08 b$ & $1.31 \mathrm{~b}$ & $0.52 b$ & $0.57 c$ & $0.66 b$ & $3.36 \mathrm{~b}$ \\
\hline $\mathrm{RR}$ & $O b$ & $5.44 \mathrm{a}$ & $2.18 \mathrm{a}$ & $0.79 a$ & $0.90 \mathrm{~b}$ & $1.55 a$ & $4.86 \mathrm{a}$ \\
\hline$P$-value & $0.000^{*}$ & $0.000^{*}$ & $0.000^{*}$ & $0.000^{*}$ & $0.000^{\star}$ & $0.000^{*}$ & $0.000^{*}$ \\
\hline \multicolumn{8}{|c|}{$(A) \times(B)$} \\
\hline$P$-value & $0.000^{*}$ & $0.000^{*}$ & $0.000^{*}$ & $0.000^{*}$ & $0.000^{*}$ & $0.048^{\star}$ & $0.000^{*}$ \\
\hline \multicolumn{8}{|c|}{ UVB (C) } \\
\hline+ UVB & $1.76 \mathrm{a}$ & $3.75 a$ & $1.36 \mathrm{a}$ & 0.53 & $0.96 a$ & $0.87 a$ & $3.04 a$ \\
\hline - UVB & $1.21 b$ & $2.86 b$ & $0.96 b$ & 0.49 & $0.75 b$ & $0.64 b$ & $2.42 \mathrm{~b}$ \\
\hline$P$-value & $0.027^{\star}$ & $0.000^{*}$ & $0.002^{*}$ & 0.073 & $0.000^{*}$ & $0.000^{*}$ & $0.002^{*}$ \\
\hline \multicolumn{8}{|c|}{$(A) \times(C)$} \\
\hline$P$-value & 0.105 & 0.305 & $0.006^{*}$ & $0.000^{*}$ & $0.000^{*}$ & $0.004^{*}$ & $0.000^{*}$ \\
\hline \multicolumn{8}{|c|}{$(B) \times(C)$} \\
\hline$P$-value & $0.009^{*}$ & $0.000^{*}$ & $0.000^{*}$ & $0.000^{*}$ & $0.000^{*}$ & $0.000^{*}$ & $0.009^{*}$ \\
\hline \multicolumn{8}{|c|}{$(A) \times(B) \times(C)$} \\
\hline$P$-value & 0.068 & $0.000^{*}$ & $0.000^{*}$ & $0.000^{*}$ & $0.000^{*}$ & $0.000^{*}$ & $0.000^{*}$ \\
\hline
\end{tabular}

${ }^{a}$ Values are expressed as $\mathrm{mg} 100 \mathrm{~g}^{-1} \mathrm{fw}$ except for phytofluene which is expressed as $\mu \mathrm{g} 100 \mathrm{~g}^{-1} \mathrm{fw}$. The significance of the $P$-value according three-way ANOVA is reported. Asterisk $\left(^{*}\right)$ indicates statistically significant differences at $P<0.05$. Different letters indicate statistically different means following Tukey's test $(P=0.05)$. MG, mature green; BR, breaker; RR, red ripe.

UV-B depletion ( $-55 \%$; Table 2). Similarly to what was observed at skin level, also in the flesh total chlorophyll concentration underwent the major decrease in UV-B depleted Ailsa Craig and nor fruits (Table 4).

Total Carotenoids. Total carotenoid concentration was about 2- and 3-fold higher in Ailsa Craig than in rin and nor mutants, either at skin (Table 1) or flesh level (Table 2), and in both tissues it increased with ripening (Tables $\mathbf{1}$ and 2). With the exception of genotype $x U V-B$ interaction, all the second and third level interactions significantly influenced skin total carotenoids (Table 1). More in detail, following UV-B shielding, Ailsa Craig fruits underwent an increase in skin total carotenoid concentration at the first two ripening stages $(+325 \%$ and $+30 \%$ at the $\mathrm{MG}$ and BR stage, respectively) followed by a decrease of about $-45 \%$ in RR fruits (Table 3). Conversely, nor fruits exhibited a decrease in skin carotenoid concentration of about $-73 \%$ and $-38 \%$ at the $\mathrm{MG}$ and BR stage, respectively, and no change at the RR stage, while in rin, after a slight increase at MG stage, total carotenoids decreased thereafter $(-74 \%$ and $-48 \%$ at BR and RR stage, respectively; Table 3).

$\mathrm{UV}-\mathrm{B}$ shielding and $U V-B \times$ ripening interaction did not influence total carotenoid concentration in the flesh, while a genotype-dependent effect of UV-B shielding was detected (Table 2). In fact, the influence of UV-B screening on Ailsa Craig flesh was negative at any ripening stage, the highest UV-Binduced decrease being recorded in MG fruits $(-52 \%$, Table 4). Conversely, UV-B depletion positively affected total carotenoid concentration of nor flesh at both the BR $(+169 \%)$ and RR
$(+75 \%)$ stage, while in rin it induced an increase at the $\mathrm{MG}$ $(+44 \%)$ and a decrease at the RR stage $(-56 \%$, Table 4).

Lycopene. Lycopene concentration was significantly higher in Ailsa Craig skin and flesh as compared to the two mutants (Table 1 and 2). In both tissues, this carotenoid, absent at the MG stage, started to accumulate in BR fruits and reached the highest concentration at the RR stage (Table $\mathbf{1}$ and 2). Lycopene concentration was significantly reduced by UV-B shielding at both skin and flesh level, the effect of UV-B being influenced by genotype, ripening stage, and both factors (Table 1 and 2). More in detail, due to lycopene appearance starting from BR stage, UV-B effects were obviously observed only in BR and $\mathrm{RR}$ fruits. In particular, UV-B deprivation significantly affected skin lycopene accumulation mainly at the RR stage either in Ailsa Craig $(-41 \%)$ or in the two mutants $(-58 \%$ and $-79 \%$ in nor and rin skin, respectively, Table 3). At the flesh level, each genotype showed a different behavior. In fact, while in Ailsa Craig lycopene was negatively affected by UV-B shielding ( $-35 \%$ at $\mathrm{BR}$ and $-19 \%$ at RR stage, respectively), in nor it decreased in BR fruits $(-50 \%)$ and increased in $\mathrm{RR}$ ones $(+121 \%$, Table 4). Similarly, lycopene concentration increased following UV-B depletion also in rin flesh but only at the BR stage $(+133 \%$, Table 4$)$.

$\beta$-Carotene. Three-way ANOVA revealed that Ailsa Craig skin contained about 3 -fold more $\beta$-carotene concentration than nor and rin (Table 1) and that on average $\beta$-carotene concentration progressively increased from the MG to the RR stage (Table 1). UV-B depletion significantly affected $\beta$-carotene 
Table 2. Effect of Genotype (A), Ripening Stage (B), Presence or Absence of UV-B Radiation (C), and Their Interactions on Total Chlorophyll, Total Carotenoid, Lycopene, $\beta$-Carotene, Lutein, Phytoene, and Phytofluene Concentration of Tomato Fruit Flesh ${ }^{a}$

\begin{tabular}{|c|c|c|c|c|c|c|c|}
\hline factors & $\frac{\text { tot chlor }}{\mathrm{mg} 100 \mathrm{~g}^{-1} \mathrm{fw}}$ & $\frac{\text { tot carot }}{\mathrm{mg} 100 \mathrm{~g}^{-1} \mathrm{fw}}$ & $\frac{\text { lycopene }}{{\mathrm{mg} 100 \mathrm{~g}^{-1} \mathrm{fw}}}$ & $\frac{\beta \text {-carot }}{\mathrm{mg} 100 \mathrm{~g}^{-1} \mathrm{fw}}$ & $\frac{\text { lutein }}{\mathrm{mg} 100 \mathrm{~g}^{-1} \mathrm{fw}}$ & $\frac{\text { phytoene }}{\mu \mathrm{g} 100 \mathrm{~g}^{-1} \mathrm{fw}}$ & $\begin{array}{l}\text { phytofluene } \\
\mu \mathrm{g} 100 \mathrm{~g}^{-1} \mathrm{fw}\end{array}$ \\
\hline \multicolumn{8}{|c|}{ Genotypes (A) } \\
\hline Ailsa Craig & $0.54 \mathrm{a}$ & $2.30 \mathrm{a}$ & $1.66 \mathrm{a}$ & $0.30 \mathrm{a}$ & $0.27 b$ & $86.98 a$ & $28.80 \mathrm{a}$ \\
\hline nor & $0.51 \mathrm{a}$ & $0.55 b$ & $0.11 b$ & $0.18 b$ & $0.24 b$ & $15.55 b$ & $1.89 b$ \\
\hline rin & $0.07 c$ & $0.52 b$ & $0.03 c$ & $0.10 \mathrm{c}$ & $0.41 \mathrm{a}$ & $8.65 b$ & $3.76 b$ \\
\hline$P$-value & $0.000^{*}$ & $0.000^{*}$ & $0.000^{*}$ & $0.000^{*}$ & $0.000^{*}$ & $0.000^{*}$ & $0.000^{*}$ \\
\hline \multicolumn{8}{|c|}{ Ripening (B) } \\
\hline MG & $1.12 \mathrm{a}$ & $0.58 b$ & $0 c$ & $0.10 \mathrm{c}$ & $0.49 a$ & $1.27 \mathrm{C}$ & $0 c$ \\
\hline BR & $0 \mathrm{~b}$ & $0.67 b$ & $0.27 b$ & $0.17 b$ & $0.21 b$ & $29.65 b$ & $7.60 b$ \\
\hline $\mathrm{RR}$ & $O b$ & $2.11 \mathrm{a}$ & $1.53 \mathrm{a}$ & $0.30 \mathrm{a}$ & $0.21 b$ & $80.26 a$ & $14.77 \mathrm{a}$ \\
\hline$P$-value & $0.000^{*}$ & $0.000^{*}$ & $0.000^{*}$ & $0.000^{*}$ & $0.000^{*}$ & $0.000^{*}$ & $0.000^{*}$ \\
\hline \multicolumn{8}{|c|}{$(A) \times(B)$} \\
\hline$P$-value & $0.000^{*}$ & $0.000^{*}$ & $0.000^{*}$ & $0.000^{*}$ & $0.000^{*}$ & $0.000^{*}$ & $0.000^{*}$ \\
\hline \multicolumn{8}{|c|}{ UVB (C) } \\
\hline+ UVB & $0.51 \mathrm{a}$ & 1.15 & $0.65 a$ & $0.17 b$ & 0.29 & $40.71 \mathrm{a}$ & $23.70 \mathrm{a}$ \\
\hline- UVB & $0.23 b$ & 1.11 & $0.55 b$ & $0.21 \mathrm{a}$ & 0.32 & $33.41 b$ & $3.78 b$ \\
\hline$P$-value & $0.000^{*}$ & 0.147 & $0.000^{*}$ & $0.000^{*}$ & 0.138 & $0.020^{*}$ & $0.000^{*}$ \\
\hline \multicolumn{8}{|c|}{$(A) \times(C)$} \\
\hline$P$-value & $0.000^{*}$ & $0.000^{*}$ & $0.000^{*}$ & $0.000^{*}$ & $0.000^{*}$ & 0.645 & $0.000^{*}$ \\
\hline \multicolumn{8}{|c|}{$(B) \times(C)$} \\
\hline$P$-value & $0.000^{*}$ & 0.115 & $0.000^{*}$ & $0.000^{*}$ & 0.683 & $0.001^{*}$ & $0.000^{*}$ \\
\hline \multicolumn{8}{|c|}{$(A) \times(B) \times(C)$} \\
\hline$P$-value & $0.000^{*}$ & $0.003^{*}$ & $0.000^{*}$ & $0.000^{*}$ & $0.000^{*}$ & 0.005 & $0.000^{*}$ \\
\hline
\end{tabular}

${ }^{a}$ Values are expressed as $\mathrm{mg} 100 \mathrm{~g}^{-1} \mathrm{fw}$ except for phytoene and phytofluene which are expressed as $\mu \mathrm{g} 100 \mathrm{~g}^{-1} \mathrm{fw}$. The significance of the $P$-value according three-way ANOVA is reported. Asterisk $\left(^{*}\right)$ indicates statistically significant differences at $P<0.05$. Different letters indicate statistically different means following Tukey's test $(P=0.05)$. MG, mature green; BR, breaker; RR, red ripe.

accumulation only when in combination with genotype, ripening stage, or both factors (Table 1). Looking more in depth at the behavior of each genotype, the negative effect of UV-B shielding on skin $\beta$-carotene concentration seemed particularly evident in nor at MG $(-96 \%)$ and BR $(-92 \%)$ fruits (Table 3), while at these ripening stages $U V-B$ depletion led to a major accumulation of this carotenoid in Ailsa Craig skin $(+36 \%$ and $+65 \%$, at the MG and BR stage, respectively; Table 3).

$\beta$-Carotene accumulated at different concentrations in the three genotypes also at the flesh level, being highest in Ailsa Craig and lowest in rin fruits (Table 2), and its concentration was found to increase as the ripening process proceeded (Table 2). Fruits ripened under $\mathrm{UV}-\mathrm{B}$ depleted conditions contained higher flesh $\beta$-carotene concentration than control ones $(+24 \%)$. This behavior was shown by Ailsa Craig starting from the BR stage $(+39 \%$ and $+109 \%$ at the BR and RR stage, respectively) and by BR nor flesh, this latter showing a 9-fold increase in UV-B depleted sample, while in $\mathrm{RR}$ rin flesh $\beta$-carotene underwent a $-64 \%$ decrease following UV-B shielding (Table 4).

Lutein. Skin lutein concentration did not show the huge differences among the genotypes observed for the previous carotenoids. Ailsa Craig and rin mutant contained in fact the same lutein amount, which was about $75 \%$ higher than the nor one (Table 1). The ripening stage influenced lutein concentrations, the highest and lowest amounts being measured in MG and BR skin, respectively. Ripening under UV-B shielded conditions induced a significant decrease in skin lutein concentration $(-22 \%)$, and the effects of UV-B screening were found to differ among the three genotypes or as a function of ripening stage (Table 1). In particular, following UV-B depletion, Ailsa Craig and $\operatorname{rin}$ RR fruits exhibited a decrease of about $-84 \%$ and $-51 \%$, respectively, while nor RR skin seemed to be unaffected (Table 3). More complex was the effect of $\mathrm{UV}-\mathrm{B}$ depletion on MG and BR fruits. In fact, while Ailsa Craig accumulated more skin lutein $(+486 \%$ and $+77 \%$ at $\mathrm{MG}$ and $\mathrm{BR}$ stage, respectively), the concentration of this carotenoid was found to decrease in MG nor $(-68 \%)$ and in BR rin skin $(-86 \%$, Table 3$)$.

At the flesh level, rin mutant contained the highest lutein concentration, which was about 1.5-fold that of Ailsa Craig and nor fruits (Table 2). Lutein mainly accumulated in $\mathrm{MG}$ flesh, thereafter decreasing to similar amounts at BR and RR stages ( $-57 \%$, Table 2$)$, although this occurred only in the two mutants, while Ailsa Craig showed similar lutein concentration at any ripening stage (data not shown). UV-B depletion affected lutein concentration differently in the three genotypes, and similarly to what was detected for flesh total carotenoids, the effects of $\mathrm{UV}-\mathrm{B}$ shielding were not dependent on ripening stage but on the combination of ripening stage and genotype (Table 2). In particular, Ailsa Craig and rin showed, respectively, a decrease $(-56 \%)$ or an increase $(+38 \%)$ at the $\mathrm{MG}$ stage and the opposite trend at the RR stage $(+75 \%$ and $-61 \%$ in Ailsa Craig and rin, respectively; Table 4). In nor flesh, lutein concentration, which was extremely low in BR and RR control fruits, dramatically increased following UV-B depletion $(+800 \%$ and $+450 \%$ at the BR and RR stage, respectively; Table 4). 
Table 3. Skin Concentration of Total Chlorophylls, Total Carotenoids, Lycopene, $\beta$-Carotene, Lutein, Phytoene, and Phytofluene of Ailsa Craig, nor, and rin Tomato Fruits Ripened under Control (C) or UV-B Depleted Conditions (-UVB) and Harvested at the Mature Green (MG), Breaker (BR), or Red Ripe (RR) Stage ${ }^{a}$

\begin{tabular}{|c|c|c|c|c|c|c|c|}
\hline & & & & & & & \\
\hline & & C & -UVB & C & -UVB & C & -UVB \\
\hline tot chlorophyll, $\mathrm{mg} 100 \mathrm{~g}^{-1} \mathrm{fw}$ & $M G$ & $14.26 \pm 0.27$ & $14.00 \pm 0.10$ & $1.15 \pm 0.03$ & $0.68 \pm 0.03$ & $0.45 \pm 0.03$ & $0.51 \pm 0.04$ \\
\hline & $\mathrm{BR}$ & nd & nd & nd & nd & nd & nd \\
\hline & $\mathrm{RR}$ & nd & nd & nd & nd & nd & nd \\
\hline tot carotenoids, mg $100 \mathrm{~g}^{-1} \mathrm{fw}$ & $M G$ & $0.57 \pm 0.16$ & $2.42 \pm 0.24$ & $1.63 \pm 0.06$ & $0.45 \pm 0.01$ & $1.52 \pm 0.03$ & $1.79 \pm 0.02$ \\
\hline & $\mathrm{BR}$ & $5.84 \pm 0.15$ & $7.59 \pm 0.22$ & $1.17 \pm 0.18$ & $0.72 \pm 0.12$ & $2.52 \pm 0.07$ & $0.66 \pm 0.21$ \\
\hline & $\mathrm{RR}$ & $13.71 \pm 0.25$ & $7.52 \pm 1.15$ & $2.69 \pm 0.39$ & $2.49 \pm 0.07$ & $4.08 \pm 0.25$ & $2.13 \pm 0.19$ \\
\hline lycopene, $\mathrm{mg} 100 \mathrm{~g}^{-1} \mathrm{fw}$ & $M G$ & nd & nd & nd & nd & nd & nd \\
\hline & $\mathrm{BR}$ & $3.58 \pm 0.18$ & $3.80 \pm 0.06$ & $0.09 \pm 0.03$ & $0.07 \pm 0.01$ & $0.28 \pm 0.05$ & $0.05 \pm 0.01$ \\
\hline & $\mathrm{RR}$ & $7.79 \pm 0.69$ & $4.57 \pm 0.83$ & $0.19 \pm 0.01$ & $0.08 \pm 0.01$ & $0.38 \pm 0.02$ & $0.08 \pm 0.02$ \\
\hline$\beta$-carotene, $\mathrm{mg} 100 \mathrm{~g}^{-1} \mathrm{fw}$ & $M G$ & $0.28 \pm 0.02$ & $0.38 \pm 0.01$ & $0.27 \pm 0.01$ & $0.01 \pm 0.01$ & $0.25 \pm 0.01$ & $0.20 \pm 0.01$ \\
\hline & $\mathrm{BR}$ & $0.93 \pm 0.08$ & $1.53 \pm 0.10$ & $0.25 \pm 0.01$ & $0.02 \pm 0.01$ & $0.22 \pm 0.04$ & $0.18 \pm 0.05$ \\
\hline & $\mathrm{RR}$ & $1.55 \pm 0.01$ & $1.27 \pm 0.01$ & $0.57 \pm 0.06$ & $0.45 \pm 0.01$ & $0.50 \pm 0.10$ & $0.41 \pm 0.06$ \\
\hline lutein, $\mathrm{mg} 100 \mathrm{~g}^{-1} \mathrm{fw}$ & $M G$ & $0.28 \pm 0.13$ & $1.64 \pm 0.23$ & $1.36 \pm 0.07$ & $0.44 \pm 0.01$ & $1.27 \pm 0.02$ & $1.59 \pm 0.02$ \\
\hline & $\mathrm{BR}$ & $0.70 \pm 0.09$ & $1.24 \pm 0.13$ & $0.22 \pm 0.04$ & $0.17 \pm 0.01$ & $1.00 \pm 0.18$ & $0.14 \pm 0.01$ \\
\hline & $\mathrm{RR}$ & $1.84 \pm 0.26$ & $0.30 \pm 0.03$ & $0.65 \pm 0.15$ & $0.62 \pm 0.11$ & $1.36 \pm 0.04$ & $0.66 \pm 0.01$ \\
\hline phytoene, mg $100 \mathrm{~g}^{-1} \mathrm{fw}$ & $M G$ & nd & $0.39 \pm 0.01$ & nd & nd & nd & nd \\
\hline & $\mathrm{BR}$ & $0.63 \pm 0.07$ & $1.01 \pm 0.02$ & $0.60 \pm 0.15$ & $0.45 \pm 0.13$ & $1.02 \pm 0.07$ & $0.29 \pm 0.22$ \\
\hline & $\mathrm{RR}$ & $2.53 \pm 0.19$ & $1.37 \pm 0.31$ & $1.28 \pm 0.02$ & $1.34 \pm 0.14$ & $1.83 \pm 0.19$ & $0.97 \pm 0.12$ \\
\hline phytofluene, $\mu \mathrm{g} 100 \mathrm{~g}^{-1} \mathrm{fw}$ & MG & nd & nd & nd & nd & nd & nd \\
\hline & $\mathrm{BR}$ & $4.67 \pm 0.97$ & $4.87 \pm 0.51$ & $2.47 \pm 0.35$ & $2.27 \pm 0.47$ & $3.40 \pm 0.29$ & $2.05 \pm 0.35$ \\
\hline & $\mathrm{RR}$ & $4.00 \pm 0.80$ & $4.90 \pm 0.31$ & $3.77 \pm 1.17$ & $3.30 \pm 0.01$ & $9.17 \pm 1.10$ & $4.30 \pm 0.51$ \\
\hline
\end{tabular}

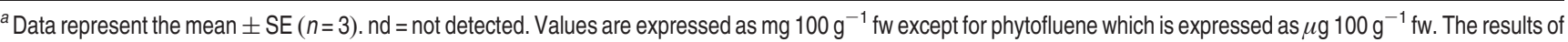
the corresponding three-way ANOVA are reported in Table 1.

Table 4. Flesh Concentration of Total Chlorophylls, Total Carotenoids, Lycopene, $\beta$-Carotene, Lutein, Phytoene, and Phytofluene of Ailsa Craig, nor, and rin Tomato Fruits Ripened under Control (C) or UV-B Depleted Conditions (-UVB) and Harvested at the Mature Green (MG), Breaker (BR), or Red Ripe (RR) Stage ${ }^{a}$

\begin{tabular}{|c|c|c|c|c|c|c|c|}
\hline & & \multicolumn{2}{|c|}{ Ailsa Craig } & \multicolumn{2}{|c|}{ nor } & \multicolumn{2}{|c|}{ rin } \\
\hline & & C & -UVB & C & -UVB & C & -UVB \\
\hline \multirow[t]{3}{*}{ tot chlorophyll, mg $100 \mathrm{~g}^{-1} \mathrm{fw}$} & $M G$ & $2.25 \pm 0.07$ & $0.97 \pm 0.01$ & $2.10 \pm 0.04$ & $0.97 \pm 0.03$ & $0.26 \pm 0.01$ & $0.15 \pm 0.02$ \\
\hline & BR & nd & nd & nd & nd & nd & nd \\
\hline & $\mathrm{RR}$ & nd & nd & nd & nd & nd & nd \\
\hline \multirow[t]{3}{*}{ tot carotenoids, $\mathrm{mg} 100 \mathrm{~g}^{-1} \mathrm{fw}$} & $M G$ & $0.61 \pm 0.01$ & $0.29 \pm 0.01$ & $0.51 \pm 0.08$ & $0.61 \pm 0.08$ & $0.61 \pm 0.02$ & $0.88 \pm 0.01$ \\
\hline & $\mathrm{BR}$ & $1.42 \pm 0.10$ & $1.25 \pm 0.07$ & $0.16 \pm 0.03$ & $0.43 \pm 0.03$ & $0.47 \pm 0.01$ & $0.43 \pm 0.07$ \\
\hline & $\mathrm{RR}$ & $5.53 \pm 0.06$ & $4.81 \pm 0.18$ & $0.59 \pm 0.08$ & $1.03 \pm 0.02$ & $0.61 \pm 0.03$ & $0.27 \pm 0.01$ \\
\hline \multirow[t]{3}{*}{ lycopene, mg $100 \mathrm{~g}^{-1} \mathrm{fw}$} & $M G$ & nd & nd & nd & nd & nd & nd \\
\hline & BR & $0.88 \pm 0.02$ & $0.57 \pm 0.11$ & $0.06 \pm 0.01$ & $0.03 \pm 0.01$ & $0.03 \pm 0.01$ & $0.07 \pm 0.01$ \\
\hline & $\mathrm{RR}$ & $4.70 \pm 0.06$ & $3.80 \pm 0.06$ & $0.19 \pm 0.01$ & $0.42 \pm 0.03$ & $0.03 \pm 0.01$ & $0.03 \pm 0.01$ \\
\hline \multirow[t]{3}{*}{$\beta$-carotene, $\mathrm{mg} 100 \mathrm{~g}^{-1} \mathrm{fw}$} & $M G$ & $0.16 \pm 0.01$ & $0.09 \pm 0.01$ & $0.09 \pm 0.01$ & $0.06 \pm 0.01$ & $0.06 \pm 0.02$ & $0.12 \pm 0.01$ \\
\hline & BR & $0.28 \pm 0.01$ & $0.39 \pm 0.05$ & $0.02 \pm 001$ & $0.20 \pm 0.01$ & $0.14 \pm 0.01$ & $0.10 \pm 0.01$ \\
\hline & $\mathrm{RR}$ & $0.35 \pm 0.01$ & $0.73 \pm 0.01$ & $0.35 \pm 0.08$ & $0.37 \pm 0.02$ & $0.11 \pm 0.04$ & $0.04 \pm 0.01$ \\
\hline \multirow[t]{3}{*}{ lutein, mg $100 \mathrm{~g}^{-1} \mathrm{fw}$} & MG & $0.45 \pm 0.01$ & $0.20 \pm 0.01$ & $0.41 \pm 0.08$ & $0.55 \pm 0.07$ & $0.55 \pm 0.01$ & $0.76 \pm 0.01$ \\
\hline & $\mathrm{BR}$ & $0.26 \pm 0.01$ & $0.25 \pm 0.03$ & $0.02 \pm 0.01$ & $0.18 \pm 0.04$ & $0.28 \pm 0.01$ & $0.25 \pm 0.07$ \\
\hline & $\mathrm{RR}$ & $0.16 \pm 0.01$ & $0.28 \pm 0.03$ & $0.04 \pm 0.02$ & $0.22 \pm 0.01$ & $0.46 \pm 0.01$ & $0.18 \pm 0.01$ \\
\hline \multirow[t]{3}{*}{ phytoene, $\mu \mathrm{g} 100 \mathrm{~g}^{-1} \mathrm{fw}$} & $M G$ & $2.63 \pm 1.19$ & $2.97 \pm 0.01$ & $0.88 \pm 0.06$ & $1.13 \pm 0.03$ & nd & nd \\
\hline & $\mathrm{BR}$ & $57.0 \pm 2.08$ & $27.3 \pm 7.84$ & $57.0 \pm 10.0$ & $11.3 \pm 0.33$ & $12.8 \pm 0.61$ & $12.5 \pm 0.28$ \\
\hline & $\mathrm{RR}$ & $216 \pm 3.06$ & $216 \pm 23.2$ & $1.97 \pm 0.07$ & $21.0 \pm 2.31$ & $18.1 \pm 0.59$ & $8.50 \pm 0.25$ \\
\hline \multirow[t]{3}{*}{ phytofluene, $\mu \mathrm{g} 100 \mathrm{~g}^{-1} \mathrm{fw}$} & $M G$ & nd & nd & nd & nd & nd & nd \\
\hline & $\mathrm{BR}$ & $32.7 \pm 1.86$ & $8.77 \pm 0.12$ & $0.13 \pm 0.02$ & $0.20 \pm 0.02$ & $0.65 \pm 0.02$ & $0.83 \pm 0.06$ \\
\hline & $\mathrm{RR}$ & $108 \pm 0.88$ & $23.3 \pm 7.84$ & $0.49 \pm 0.02$ & $0.31 \pm 0.02$ & $0.23 \pm 0.01$ & $0.58 \pm 0.04$ \\
\hline
\end{tabular}

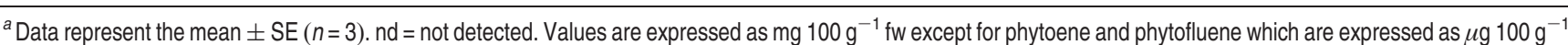
$\mathrm{fw}$. The results of the corresponding three-way ANOVA are reported in Table 2. 
A

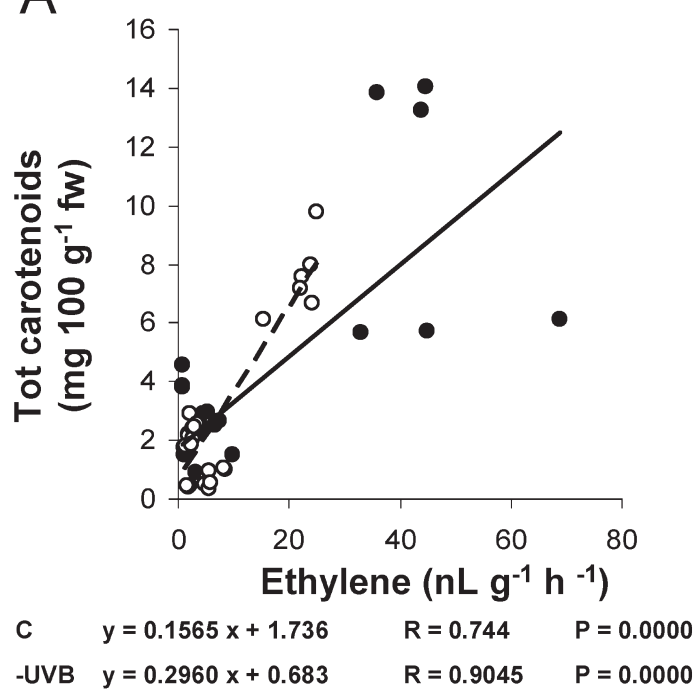

C

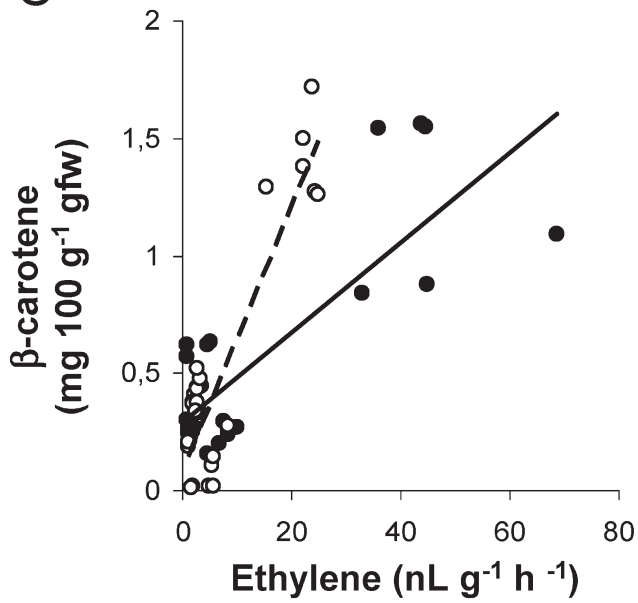

C $y=0.0192 x+0.2894 \quad R=0.8236 \quad P=0.0000$

-UVB $y=0.0566 x+0.0782 \quad R=0.9005 \quad P=0.0000$

E

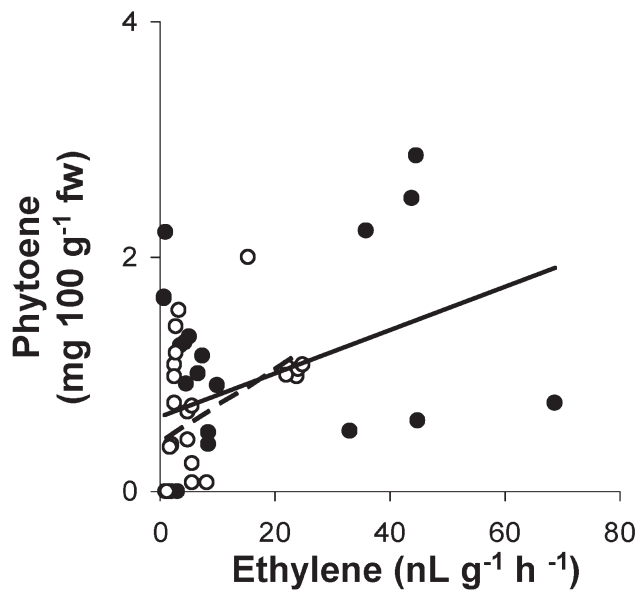

C $y=0.0185 x+0.6386 \quad R=0.3985 \quad P=0.0395$

-UVB $y=0.0313 x+0.4161 \quad R=0.4667 \quad P=0.0141$
B

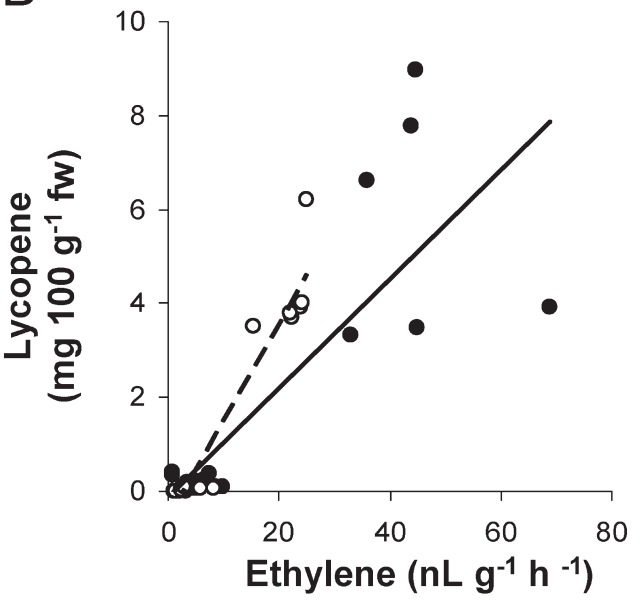

$\begin{array}{llll}\text { C } & y=0.1166 x-0.1314 & R=0.8406 & P=0.0000 \\ \text {-UVB } & y=0.2085 x-0.5766 & R=0.9198 & P=0.0000\end{array}$

D

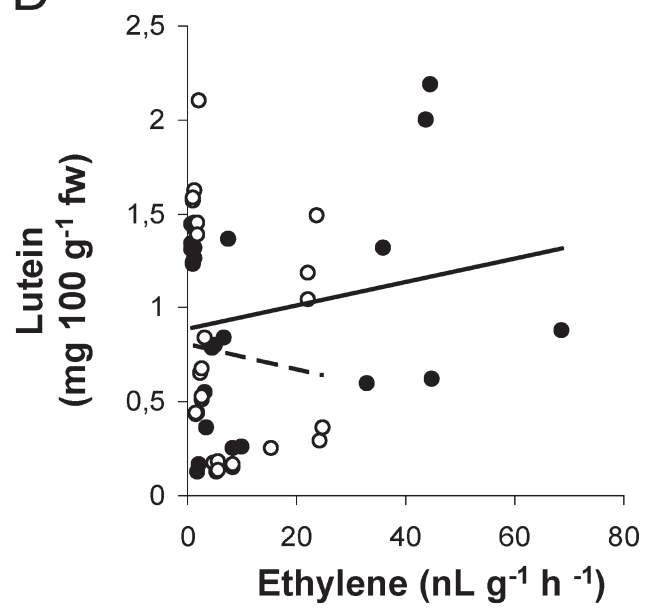

C $y=0.0062 x+0.8849 \quad R=0.2085 \quad P=0.2966$

-UVB $y=-0.0065 x+0.8051 \quad R=-0.0933 \quad P=0.6436$

F

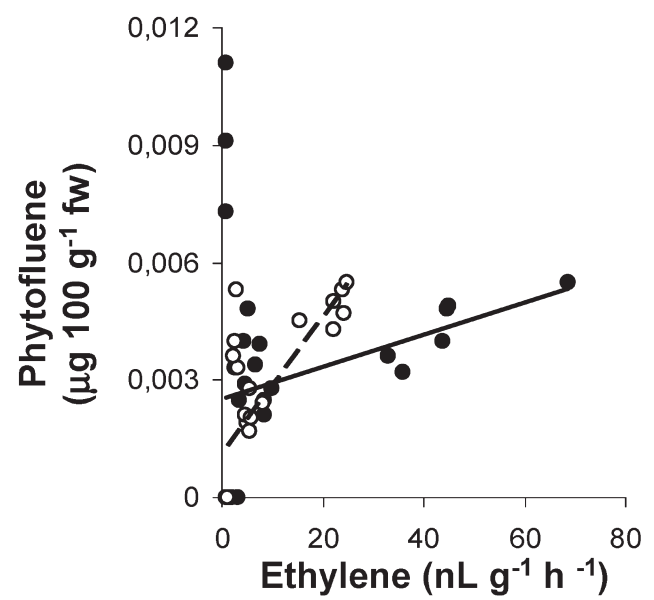

$\begin{array}{llll}C & y=0.0000 x+0.0025 & R=0.2602 & P=0.1900\end{array}$

Figure 2. Relationships between ethylene emission and skin concentration of total carotenoids, lycopene, $\beta$-carotene, lutein, phytoene, and phytofluene of control (solid line, closed circle) and UV-B depleted (dashed line, open circle) tomato fruits. Regression equations, correlation coefficients $(R)$, and the significance level $(P)$ of the correlation coefficients are reported below each plot. 


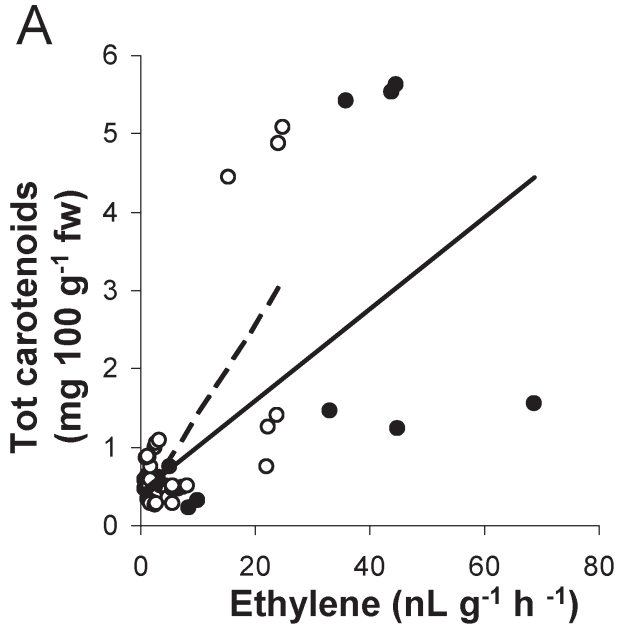

C $y=0.0584 x+0.417$

$R=0.6790 \quad P=0.0001$

-UVB $y=0.1146 x+0.2538$

$R=0.6949$

$P=0.0001$

C

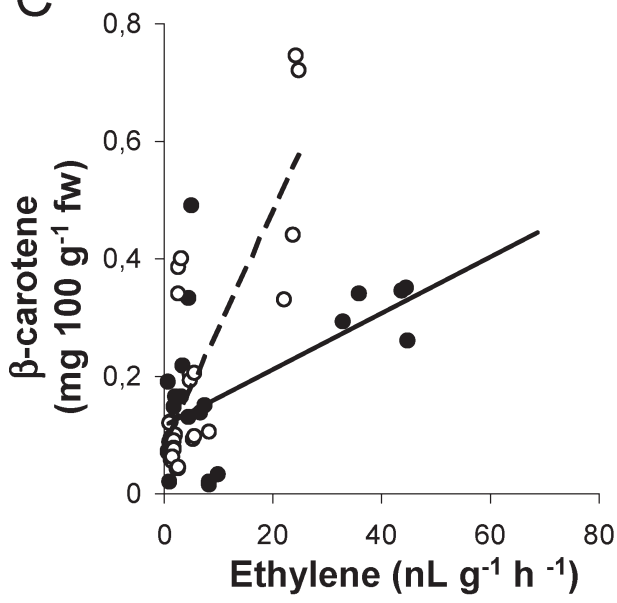

C $y=0.0048 x+0.1169 \quad R=0.5787 \quad P=0.0020$

-UVB $y=0.0201 x+0.0789 \quad R=0.7975 \quad P=0.0000$

E

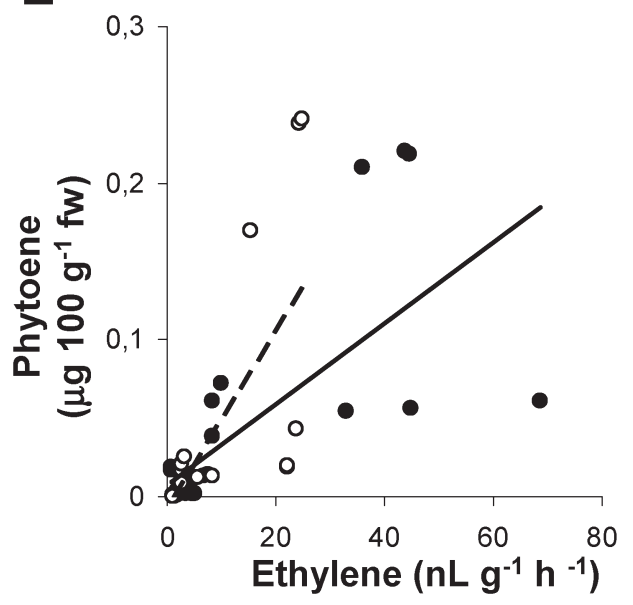

C $y=0.0026 x+0.0077$

$R=0.7137 \quad P=0.0000$

-UVB $y=0.0057 x-0.0086$

$R=0.7047 \quad P=0.0000$

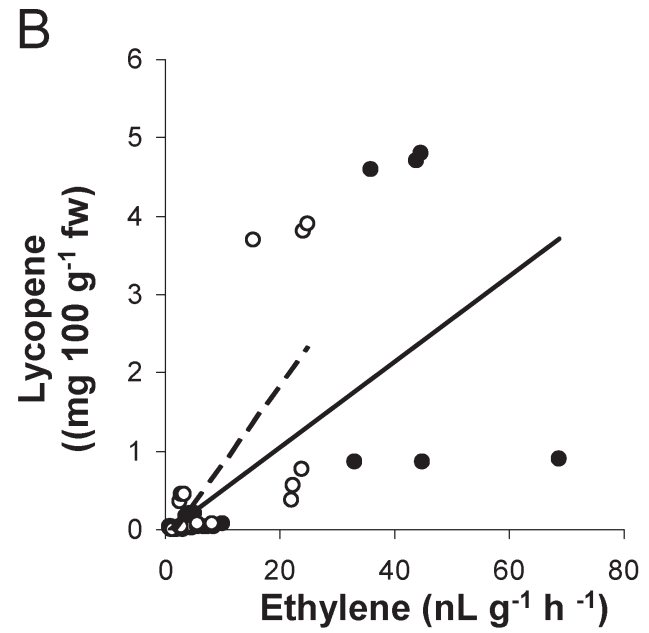

$\begin{array}{llll}\text { C } & y=0.0546 \times-0.0484 & R=0.6867 & P=0.0001 \\ \text {-UVB } & y=0.1010 x-0.1972 & R=0.7069 & P=0.0000\end{array}$

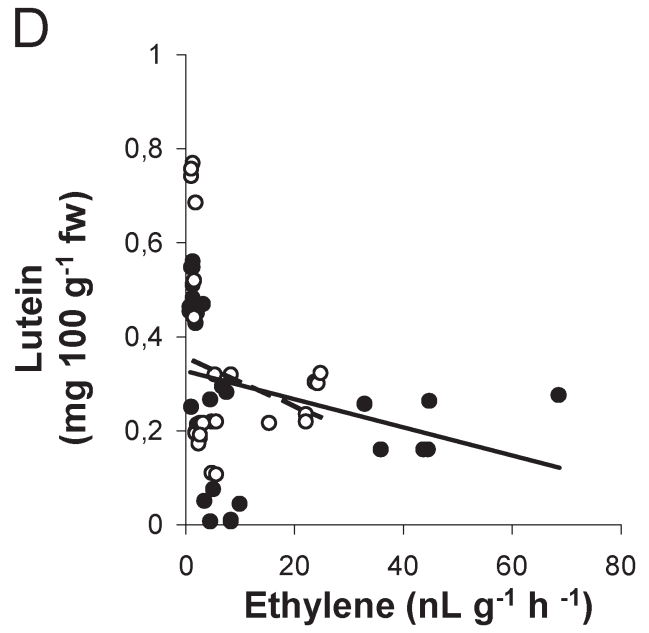

$\begin{array}{llll}\text { C } & y=-0.0300 x+0.3262 & R=0.2968 & P=0.1409 \\ \text {-UVB } & y=-0.0052 x+0.3568 & R=-0.2189 & P=0.2727\end{array}$

$\mathrm{F}$

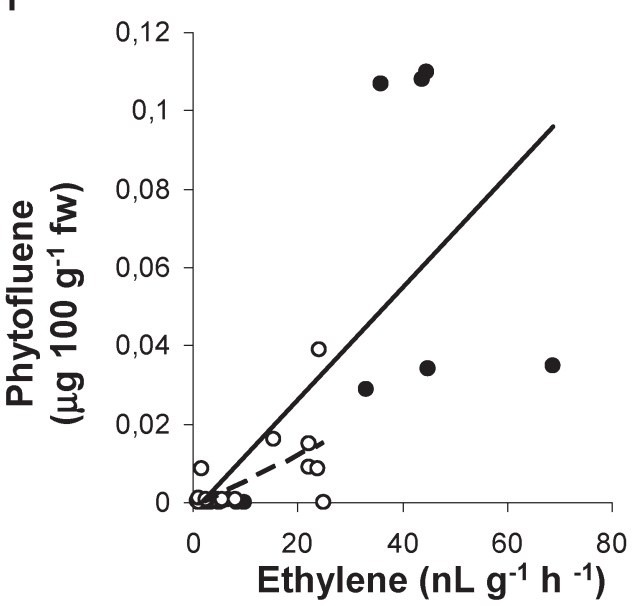

C $y=0.0014 x-0.0023 \quad R=0.7606 \quad P=0.0000$

Figure 3. Relationships between ethylene emission and flesh concentration of total carotenoids, lycopene, $\beta$-carotene, lutein, phytoene, and phytofluene of control (solid line, closed circle) and UV-B depleted (dashed line, open circle) tomato fruits. Correlation equations, correlation coefficients $(R)$, and the significance level $(P)$ of the correlation coefficients are reported below each plot. 
Phytoene. Skin and flesh phytoene concentration was significantly affected by the three factors alone or in combination, the only exception being represented by genotype $x U V-B$ interaction in the flesh tissue (Tables $\mathbf{1}$ and 2). Similarly to lycopene and $\beta$-carotene, the concentration of this carotenoid precursor was higher in Ailsa Craig skin and flesh than in the two mutants, and in any genotype, it increased during fruit ripening (Table 1). Fruits ripened without UV-B radiation contained significantly lower skin phytoene concentration than control ones $(-26 \%$, Table 1), although Ailsa Craig fruits, at BR stage, showed a $+60 \%$ increase in this carotenoid precursor (Table 3).

$\mathrm{UV}-\mathrm{B}$ shielding influenced flesh phytoene accumulation as well (Table 2), inducing at the BR stage a decrease in UV-B depleted flesh of both Ailsa Craig (-52\%) and nor (-80\%) fruits, while at the RR stage any genotype showed a different behavior, phytoene being unchanged in Ailsa Craig and increasing or decreasing in nor and rin fruits, respectively (Table 4).

Phytofluene. Any single factor as well as their interactions significantly affected phytofluene concentration at both the skin and flesh level (Tables 1 and 2). As observed for lutein, skin phytofluene displayed similar highest values in Ailsa Craig and rin (Table 1), while in the flesh Ailas Craig concentration was about 14- and 7-fold higher than in nor and rin mutants, respectively (Table 2). Similarly to the behavior of phytoene, also phytofluene accumulation was ripening-dependent, showing a progressive significant increase from not detectable values at the MG stage to the highest amounts in RR fruits, in both skin and flesh tissues (Tables 1 and 2). UV-B depleted fruits contained about $-20 \%$ and $-84 \%$ lower phytofluene concentration than control at the skin and flesh level, respectively (Tables 1 and 2). Looking more deeply at the behavior of each genotype, the negative effect of UV-B screening on skin phytofluene was evident only in rin at both the BR $(-40 \%)$ and RR stage $(-53 \%$, Table 3$)$, while a completely different trend was shown in the flesh. More in detail, in Ailsa Craig flesh phytofluene was in fact negatively affected by UV $-\mathrm{B}$ shielding $(-73 \%$ and $-78 \%$ at the BR and RR stage, respectively; Table 4). In the two mutants phytofluene concentration underwent an increase at the BR stage $(+53 \%$ and $+28 \%$ in nor and rin fruits, respectively), and at the RR stage the two genotypes exhibited a different behavior $(-37 \%$ in nor and $+152 \%$ in rin, respectively; Table 4).

Correlation between Ethylene Emission and Carotenoid Concentration in Control and UV-B Depleted Tomato Fruits. The concentration of total and single carotenoids of control and UV-B shielded fruits, as well as that of the two carotenoid precursors, was always positively correlated with ethylene production (Figures $\mathbf{2}$ and $\mathbf{3}$ ). No correlation was found in the cases of lutein, at both the skin and flesh levels (Figure 2 and 3), and of skin control phytofluene (Figure 2). It is noteworthy that the slopes of UV-B depleted lines were always about twice those of the respective controls, being even 3 - or 4 -fold higher for $\beta$-carotene at the skin and flesh level, respectively, indicating that the same ethylene production induced a more pronounced carotenoid accumulation in UV-B shielded fruits than in control ones. Conversely, the slope of flesh phytofluene correlation was higher in control than in -UVB samples (Figure 3).

\section{DISCUSSION}

Fruit ripening is a highly regulated process which requires the coordinated interplay between endogenous factors and environmental signals (24). In climacteric fruits such as tomato, ethylene is involved in the majority of ripening processes, while light seems to be specifically required for pigment accumulation (11). UV-B radiation has been reported to stimulate ethylene production in green tissues, as oat leaf segments (25), pear shoots (26), Arabidopsis (27), tobacco (28), and tomato (29) leaves, by the ROSmediated signaling route (30). However, to our knowledge, this is the first report of a positive influence of natural $\mathrm{UV}-\mathrm{B}$ radiation on ripening ethylene, as clearly indicated by the marked significant decrease of ethylene production following $\mathrm{UV}-\mathrm{B}$ depletion (Figure 1). Recently, Nakano and co-workers (31) demonstrated that ripening-related autocatalytic ethylene synthesis in detached persimmon (Diospyros kaki Thunb.) fruits was initiated by a burst of drought-induced ethylene production in response to fruit harvesting. Expression analyses of the multigene families encoding ACS and ACO suggested that the rin gene may be important in regulating ethylene synthesis during the transition from system 1 to system 2 mode of ethylene synthesis (32). Moreover, the evidence that the lack of ripening ethylene in nor and rin is due to a deficiency in appropriate developmental signals rather than to genetic lesions in ethylene biosynthetic genes supports the hypothesis that nor and rin may influence ripening aspects also independently from ethylene control (24). In the present experiment, the observation that UV-B depletion affected ethylene synthesis only in Ailsa Craig suggests that functional rin and nor genes are required for UVB-mediated ethylene production. Further analyses are however needed to establish whether UVB-dependent signaling directly modulates nor and rin gene expression or if it acts on downstream components of the ethylene biosynthetic machinery. Together with the evidence that such an effect occurred starting from the breaker stage, the aforementioned results also suggest a triggering role for $\mathrm{UV}-\mathrm{B}$ radiation during the transition from system 1 to system 2 ethylene synthesis, although this hypothesis should be validated by expression analyses of the different ACS and ACO genes.

Ethylene controls many aspects linked to climacteric fruit ripening $(13,33)$. In ripening Japanese apricot fruits, it has been shown to stimulate expression of constitutive genes involved in carotenoid biosynthesis (34). Moreover, exogenous ethylene treatments were found effective in enhancing carotenoid accumulation also in nonclimateric fruits such as citrus (35) and in fruits exhibiting a wide range of ethylene production and respiratory rate, such as pepper (36). The minor carotenoid concentration exhibited by the two mutants as compared to Ailsa Craig confirms the strict control exerted by ethylene on the synthesis of these metabolites. It is however noteworthy that in rin lutein behaved in a different way, being accumulated at the same level as in Ailsa Craig in the skin and even showing the highest value in the flesh. Since $\beta$-carotene and lutein synthesis proceeds through two different routes involving only lycopene $\beta$-cyclase (LCY-B and the chromoplast-specific one, CYC-B) or both lycopene $\beta$ - and lycopene $\varepsilon$-cyclase, respectively (37), different regulatory mechanisms probably act on these pathways during ripening. Moreover, the different behavior shown by rin and nor mutants suggests a different role for rin and nor genes in lutein metabolism.

Light plays a pivotal and double role in pigment accumulation, being necessary for their synthesis but also acting as a promoter of oxidative stress. Studying the progression of photo-oxidative stress in detached tomato fruits under natural sun irradiance, Torres et al. (38) demonstrated that natural UV radiation was not responsible for the observed chlorophyll bleaching. In the present experiment, chlorophyll accumulation was negatively affected by $\mathrm{UV}-\mathrm{B}$ depletion, indicating that natural $\mathrm{UV}-\mathrm{B}$ light is instead specifically required for chlorophyll synthesis.

The control played by UV-B radiation on carotenoid accumulation was particularly evident at the skin level at the RR stage, when total and single carotenoids, as well as their precursors, were less concentrated in UV-B shielded fruits (Table 1). Leaf carotenoid biosynthesis is well-known to be controlled by light, 
which stimulates isopentenyl diphosphate isomerase activity (39) and Psy gene transcription (9), through the control played phytochrome and/or UV-B receptors $(9,10)$. Light has been reported to influence carotenoid accumulation also in tomato fruits through the control of multiple fruit-localized phytochromes (11). Moreover, different behaviors attributable to the presence of $\mathrm{UV}-\mathrm{B}$ radiation have been described in three tomato genotypes, which exhibited increased or decreased carotenoid accumulation following UV-B depletion (17). Similarly, in the present study, carotenoid content and profile were differently affected by UV-B shielding in the three genotypes, at both the skin and flesh level, and in a ripeningdependent manner, suggesting that $\mathrm{UV}-\mathrm{B}$ radiation may somehow interact with endogenous ripening factors, among which ethylene seems to be the best candidate. Differently from what was reported by Alba and co-workers (2000), who demonstrated that phytochrome-mediated control of fruit carotenogenesis was independent from ethylene biosynthesis, our data clearly showed that in Ailsa Craig fruits UV-B radiation influenced carotenoid accumulation by regulating ethylene production. However, the observation that UV-B depletion also affect carotenoid content and/or composition of nor and rin, which are unable to produce climacteric ethylene, led us to hypothesize that UV-B may also act independently of ethylene signaling. The correlations between ethylene evolution and carotenoid accumulation, performed separately for control and UV-B shielded fruits confirm this hypothesis. In fact, correlation plots clearly indicate that the same ethylene production corresponds to an about double carotenoid accumulation in $\mathrm{UV}-\mathrm{B}$ shielded fruits, either at the skin or flesh level.

The different behavior of lutein, whose accumulation never correlated with ethylene evolution, again suggests that the branching point in the carotenoid pathway represented by the two different cyclization enzymes may be differently regulated by ethylene. During citrus degreening with exogenous ethylene, Rodrigo and Zacarias (35) indeed observed an ethylene-dependent up-regulation of carotenoid biosynthetic genes involved in phytoene formation and desaturation and of lycopene $\beta$-cyclase, while the expression of lycopene $\varepsilon$-cyclase, responsible for lutein synthesis, was found to be down-regulated by ethylene, thus redirecting the metabolic flux toward $\beta-\beta$ carotenoids. Moreover, the observation that $\beta$-carotene correlations exhibited a higher difference between control and UVB-shielded slopes in comparison to phytoene and lycopene ones (Figures 2 and 3) suggests a particular sensitivity of lycopene $\beta$-cyclase to UV-B radiation. Differently from what was observed for lycopene, $\beta$-carotene, and phytoene, at a given ethylene production, flesh phytofluene accumulated more in control fruits than in UV-B shielded ones, indicating a positive, ethylene-independent influence of $\mathrm{UV}-\mathrm{B}$ radiation on phytoene desaturase, although a major phytofluene accumulation simply due to the lowest conversion rate to lycopene and following carotenoids cannot be excluded as well.

In conclusion, the influence of natural $\mathrm{UV}-\mathrm{B}$ radiation on carotenoid metabolism is rather complex, involving both ethylene-dependent and ethylene-independent mechanisms, which seem to act in an antagonistic way, resulting in a positive or negative influence on carotenoid accumulation, respectively. Moreover, the present results suggest a role for functional nor and rin genes in UVB-mediated production of climacteric ethylene. Further experiments on gene expression analyses, together with pharmacological treatments with inhibitors of ethylene synthesis or perception, will provide additional information on the interplay between ethylene and $\mathrm{UV}-\mathrm{B}$ light during tomato fruit ripening.

\section{ABBREVIATIONS USED}

$\mathrm{UV}-\mathrm{B}$, ultraviolet $\mathrm{B}$; Psy, phytoene synthase; rin, ripeninginhibitor; nor, nonripening; BHT, butylated hydroxytoluene; THF, tetrahydrofuran; MG, mature green; BR, breaker; RR, red ripe.

\section{ACKNOWLEDGMENT}

We gratefully acknowledge C.M. Rick Tomato Genetics Resource Center (Dept. of Plant Sciences, University of California Davis, Davis, CA, USA) for providing Ailsa Craig, nor, and rin tomato seeds. We wish to thank Prof. Alberto Pardossi (Dipartimento di Biologia delle Piante Agrarie, University of Pisa, Pisa, Italy) for hosting tunnels for field experiments and Dr. Luca Gianfranceschi (Department of Biomolecular Sciences and Biotechnology, University of Milan, Milan, Italy) for helpful comments to the manuscript.

\section{LITERATURE CITED}

(1) Semel, Y.; Schauer, N.; Roessner, U.; Zamir, D.; Fernie, A. R. Metabolite analysis for the comparison of irrigated and non-irrigated field-grown tomato of varying genotype. Metabolomics 2007, 3, 289-295.

(2) Carrari, F.; Baxter, C.; Usadel, B.; Urbanczyk-Wochniak, E.; Zanor, M.-I.; Nunes-Nesi, A.; Nikiforanova, V.; Cantero, D.; Ratzka, A.; Pauly, M.; Sweetlove, L. J.; Fernie, A. R. Integrated analysis of metabolite and transcript levels reveals the metabolic shifts that underlie tomato fruit development and highlight regulatory aspects of metabolic network behaviour. Plant Physiol. 2006, 142, 1380 1396.

(3) Ulm, R.; Nagy, F. Signalling and gene regulation in response to ultraviolet light. Curr. Opin. Plant Biol. 2005, 8, 477-482.

(4) Frohnmeyer, H.; Staiger, D. Ultraviolet-B radiation-mediated responses in plants. Balancing damage and protection. Plant Physiol. 2003, 133, 1420-1428.

(5) Brown, B. A.; Cloix, C.; Jiang, G. H.; Kaiserli, E.; Herzyk, P.; Kliebenstein, D. J.; Jenkins, G.I. A UV-B-specific signaling component orchestrates plant UV protection. Proc. Natl. Acad. Sci. U.S.A. 2005, 102, 18225-18230.

(6) Oravecz, A.; Baumann, A.; Mate, Z.; Brzezinska, A.; Molinier, J.; Oakeley, E. J.; Adam, E.; Schafer, E.; Nagy, F.; Ulm, R. CONSTITUTIVELY PHOTOMORPHOGENIC1 is required for the UV-B response in Arabidopsis. Plant Cell 2006, 18, 1975-1990.

(7) Ulm, R.; Baumann, A.; Oravecz, A.; Mate, Z.; Adam, E.; Oakeley, E. J.; Schafer, E.; Nagy, F. Genome-wide analysis of gene expression reveals function of the bZIP transcription factor HY5 in the UV-B response of Arabidopsis. Proc. Natl. Acad. Sci. U.S.A. 2004, 101, 1397-1402.

(8) Favory, J.-J.; Stec, A.; Gruber, H.; Rizzini, L.; Oravecz, A.; Funk, M.; Albert, A.; Cloix, C.; Jenkins, G.; Oakeley, E.; Seidlitz, H.; Nagy, F.; Ulm, R. Interaction of COP1 and UVR8 regulates UV-Binduced photomorphogenesis and stress acclimation in Arabidopsis. EMBO J. 2009, 28, 591-601.

(9) Von Lintig, J.; Welsch, R.; Bonk, M.; Giuliano, G.; Batschauer, A.; Kleinig, H. Light-stimulated carotenoid biosynthesis occurs at the level of phytoene synthase expression and is mediated by phytochrome in Sinapis alba and Arabidopsis thaliana seedlings. Plant $J$. 1997, 12, 625-634.

(10) Stephanou, M.; Manetas, Y. The effects of seasons, exposure, enhanced UV-B radiation and water stress on leaf epicuticular and internal UV-B absorbing capacity of Cistus creticus: a Mediterranean field study. J. Exp. Bot. 1997, 48, 1977-1985.

(11) Alba, R.; Crdonnier-Pratt, M.-M.; Pratt, L. H. Fruit-localized phytochromes regulate lycopene accumulation independently of ethylene production in tomato. Plant Physiol. 2000, 123, 363-370.

(12) Abeles, F. B.; Morgan, P. W.; Saltveit, M. E., Jr. Ethylene in Plant Biology, 2nd ed.; Academic Press, Inc.: San Diego, CA, 2004.

(13) Barry, C. S.; Giovannoni, J. J. Ethylene and fruit ripening. J. Plant Growth Regul. 2007, 26, 143-159. 
(14) Pierik, R.; Cuppens, M. L. C.; Voesenek, L. A. C. J.; Visser, E. J. W. Interactions between ethylene and gibberellins in phytochromemediated shade avoidance responses in tobacco. Plant Physiol. 2004, 136, 2928-2936.

(15) Vangronsveld, J.; Clijsters, H.; Van Poucke, M. Phytochromecontrolled ethylene biosynthesis of intact etiolated bean seedlings. Planta 1988, 174, 19-24.

(16) Finlayson, S. A.; Lee, I.-J.; Morgan, P. W. Phytochrome B and the regulation of circadian ethylene production in sorghum. Plant Physiol. 1998, 116, 17-25.

(17) Giuntini, D.; Graziani, G.; Lercari, B.; Fogliano, V.; Soldatini, G. F.; Ranieri, A. Changes in carotenoid and ascorbic acid contents in fruits of different tomato genotypes related to the depletion of UV-B radiation. J. Agric. Food Chem. 2005, 53, 3174-3181.

(18) Vrebalov, J.; Ruezinsky, D.; Padmanabhan, V.; White, R.; Medrano, D.; Drake, R.; Schuch, W.; Giovannoni, J. A MADS-Box gene necessary for fruit ripening at the tomato ripening-inhibitor (rin) locus. Science 2002, 296, 343-346.

(19) Ito, Y.; Kitagawa, M.; Ihashi, N.; Yabe, K.; Kimbara, J.; Yasuda, J.; Ito, H.; Inakuma, T.; Hiroi, S.; Kasumi, T. DNA-binding specificity, transcriptional activation potential, and the rin mutation effect for the tomato fruit-ripening regulator RIN. Plant J. 2008, 55, 212-223.

(20) Moore, S.; Vrebalov, J.; Payton, P.; Giovannoni, J. Use of genomics tools to isolate key ripening genes and analyse fruit maturation in tomato. J. Exp. Bot. 2002, 53, 2023-2030.

(21) Giuntini, D.; Lazzzeri, V.; Calvenzani, V.; Dall'Asta, C.; Galaverna, G.; Tonelli, C.; Petroni, C.; Ranieri, A. Flavonoid profiling and biosynthetic gene expression in flesh and peel of two tomato genotypes grown under UV-B-depleted conditions during ripening. J. Agric. Food Chem. 2008, 56, 5905-5915.

(22) Grierson, D.; Kader, A. A. Fruit ripening and quality. In The Tomato Crop; Atherton, J., Rudich, G., Eds.; Chapman and Hall: London, 1986; pp 241-280.

(23) Mensuali Sodi, A.; Panizza, M.; Tognoni, F. Quantification of ethylene losses in different container-seal systems and comparison of biotic and abiotic contributions to ethylene accumulation in cultured tissues. Physiol. Plant. 1992, 84, 472-476.

(24) Adams-Phillips, L.; Barry, C.; Giovannoni, J. Signal transduction systems regulating fruit ripening. Trends Plant Sci. 2004, 9, 331-338.

(25) Corbineau, F.; Rudnicki, R. M.; Goszczynska, D. M.; Come, D. The effect of light quality on ethylene production in leaves of oat seedlings (Avena sativa L.). Environ. Exp. Bot. 1995, 35, 227-233.

(26) Predieri, S.; Norman, H. A.; Krizek, D. T.; Pillai, P.; Mirecki, R. M.; Zimmerman, R. H. Influence of UV-B radiation on membrane lipid composition and ethylene evolution in doyenne d'hiver pear shoots grown in vitro under different photosynthetic photon fluxes. Environ. Exp. Bot. 1995, 35, 151-160.

(27) A-H-Mackerness, S.; Surplus, S. L.; Blake, P.; John, C. F.; BuchananWollaston, V.; Jordan, B. R.; Thomas, B. UV-B induced stress and changes in gene expression in Arabidopsis thaliana: Role of signaling pathways controlled by jasmonic acid, ethylene and reactive oxygen species. Plant Cell Environ. 1999, 22, 1413-1424.

(28) Nara, A.; Takeuchi, Y. Ethylene evolution from tobacco leaves irradiated with UV-B. J. Plant Res. 2002, 115, 247-253.
(29) An, L.; Xu, X.; Tang, H.; Zhang, M.; Hou, Z.; Liu, Y.; Zhao, Z.; Feng, H.; Xu, S.; Wang, X. Ethylene production and 1-aminocyclopropane-1-carboxylate (ACC) synthase gene expression in tomato (Lycopersicon esculentum Mill.) leaves under enhanced UV-B radiation. J. Integr. Plant Biol. 2006, 48, 1190-1196.

(30) A-H-Mackerness, S. Plant responses to ultraviolet-B (UV-B: 280-320 nm) stress: What are the key regulators? Plant Growth Regul. 2000, 32, 27-39.

(31) Nakano, R.; Ogura, E.; Kubo, Y.; Inaba, A. Ethylene biosynthesis in detached young persimmon fruit is initiated in calyx and modulated by water loss from the fruit. Plant Physiol. 2003, 131, 276286.

(32) Barry, C. S.; Llop-Tous, M. I.; Grierson, D. The regulation of 1-aminocyclopropane-1-carboxylic acid synthase gene expression during the transition from system-1 to system-2 ethylene synthesis in tomato. Plant Physiol. 2000, 123, 979-986.

(33) Alba, R.; Payton, P.; Fei, Z.; McQuinn, R.; Debbie, P.; Martin, G. B.; Tanksley, S. D.; Giovannoni, J. J. Transcriptome and Selected Metabolite Analyses Reveal Multiple Points of Ethylene Control during Tomato Fruit Development. Plant Cell. 2005, 17, 29542965.

(34) Kita, M.; Kato, M.; Ban, Y.; Honda, C.; Yaegaki, H.; Ikoma, Y.; Moriguchi, T. Carotenoid Accumulation in Japanese Apricot (Prunus mume Siebold \& Zucc.): Molecular Analysis of Carotenogenic Gene Expression and Ethylene Regulation. J. Agric. Food Chem. 2007, 55, 3414-3420.

(35) Rodrigo, M. J.; Zacarias, L. Effect of Postharvest Ethylene Treatment on Carotenoid Accumulation and the Expression of Carotenoid Biosynthetic Genes in the Flavedo of Orange (Citrus sinensis L. Osbeck) Fruit. Postharvest Biol. Technol. 2007, 43, 14-22.

(36) Fox, A. J.; Pozo-Insfran, D.; Lee, J. H.; Sargent, S. A.; Talcott, S. T. Ripening-induced chemical and antioxidant changes in bell peppers as affected by harvest maturity and postharvest ethylene exposure. HortScience 2005, 40, 732-736.

(37) Ronen, G.; Carmel-Goren, L.; Zamir, D.; Hirschberg, J. An alternative pathway to $\beta$-carotene formation in plant chromoplasts discovered by map-based cloning of beta and old-gold color mutations in tomato. Proc. Natl. Acad. Sci. U.S.A. 2000, 97, 11102-11107.

(38) Torres, C. A.; Andrews, P. K.; Davies, N. M. Physiological and biochemical responses of fruit exocarp of tomato (Lycopersicon esculentum Mill.) mutants to natural photo-oxidative conditions. J. Exp. Bot. 2006, 57, 1933-1947.

(39) Albrecht, M.; Sandmann, G. Light-stimulated carotenoid biosynthesis during transformation of maize etioplasts is regulated by increases activity of isopentenyl pyrophosphate isomerase. Plant Physiol. 1994, 105, 529-534.

Received for review July 23, 2009. Revised manuscript received September 23, 2009. Accepted October 20, 2009. The present research was supported by a grant from the Italian Ministry of University and Research (PRIN Project 2006) to A.R. and K.P., by the European Union Framework Programme VI FLORA Project to C.T., and by funds of the University of Pisa to A.R. 